\title{
Introductory Thoughts
}

\author{
Tamara Shefer
}

Located far from the geopolitical context of the authors in this volume, in the post-apartheid South African context of decades of 'transforming' higher education, re-energised by the last few years of young people's calls to decolonise the university, it was with some surprise that I found myself identifying, at multiple moments, with the sentiments and arguments expressed in this volume. Indeed, I doubt there are many scholars located in any university across the globe at this moment in time who will not recognise and find resonance with the powerful narratives articulated here, notwithstanding their predominant location in a European and a global northern context.

This book joins a growing and increasingly urgent conversation about contemporary hegemonic practices in the university in globalised contexts shaped by neoliberal capitalist imperatives. While our different historical and geopolitical contexts clearly present nuanced experiences for us in our different nation-state materialities, we also have much in common given the seamless, 'liquid' flow of globalised institutional frameworks and of higher education in current times. For example, at the same time as we in South Africa have been over the last few years facing probably one of the most intense challenges to 'business as usual' in the academy, the neoliberal, consumer capitalist grip on our universities was similarly intensifying. As Achille Mbembe (2015a, n.p.), well known critical humanities scholar, puts it:

While this mini cultural revolution was unfolding, the post-apartheid governing classes further ensconced themselves in a bureaucratic rationality that considered market metrics the ultimate indicator of who and what mattered.

This is, in my view, one of the major contributions of this book: to provide a theoretically informed and 'evidence-based' account of the shape of this 'bureaucratic rationality'. In this respect the book adds to and strengthens the larger critique of the local and globalised neoliberalisation of the university. Many of the chapters position themselves within the foundational framework of Bauman's 'liquid modernity' (Bauman, 2000) and Bauman \& Donskis' further iterations of 'moral blindness' and 'liquid evil' (Bauman \& Donskis, 2013; 2016) to advance the critique of the university under these conditions and to craft a powerful and detailed picture of how neoliberal discourse and 
practices currently shape universities globally. Given the centrality of Bauman and Donskis' thinking and the way in which an engagement with the late Leonidas Donskis in person, and through his intellectual brilliance has so clearly been a key part of the conceptual and inspirational development of the book, it is particularly significant and poignant that Leonidas is an author of a chapter in the book and acknowledged as editor on the book. Having had the privilege to spend time with Leonidas when he visited South Africa to present a generous series of lectures related to his then newly launched book with Bauman (Bauman \& Donskis, 2016) and having been present with some of the authors at a panel related to this book at a memorial conference for Leonidas in Kaunas in 2017, I am intensely aware of how important he was to the scholars here, as he was to so many across the globe. This chapter, indeed a special gift to the book and its readers, may well have been one of the last pieces of scholarship he worked on, and his legacy is threaded through the pages of this book as a continuing inspiration from this wonderful thinker and friend.

The chapters together and separately advance the account of this insidious creep of neoliberalism in contemporary universities, showing how it is entangled with global hegemonies of capitalism and the reproduction of the continued relations of power on the basis of classed, gendered, raced, aged, sexualised, citizenship, embodiment, and other social divides - what Donskis refers to as 'the unholy alliance of local and international ideologues of neoliberalism, libertarian preachers of free-market fundamentalism, and political technocrats', which is argued and shown to place immense pressures on both academics and students. Aptly described by Van Loon, such an entangled force 'intervenes, seduces, manipulates and then withdraws again in the shadows, like an intangible, shallow Prometheus. What this label "neoliberal" perhaps more accurately stands for is the recapturing and securing of a reproduction of a social order most commonly described as "capitalist" (Boltanski \& Chiapello, 2017), but manifesting itself in a more limited fashion as the naturalisation of white, male bourgeois privilege'.

A range of profoundly negative and destructive effects of the 'unholy alliance' are described and unpacked in the different chapters. Donskis for example speaks about 'the post-academic university', which for him, as for others in this book and in other scholarly works, results in a 'shallow scholarship', articulated so well as:

An awkward amalgam of medieval academic ritual, specialisation, a blatant and blunt denial of the role of the humanities in modern society, managerialism and shallowness allows a perfect scene for such a 
post-academic university, the playground for enormous pressures, the latter coming from technocratic forces disguised as the genuine voices of liberty and democracy - first and foremost, the market-oriented forms of determinism and fatalism with no room left for the principle of alternative, including critical thought and self-questioning.

A key project of many of the chapters is the helpful and well-argued critique of the marketisation (described elsewhere as 'uberisation', 'Macdonaldism') and corporatisation (with digitalisation as a key component) of the university, shaped by larger global capitalist imperatives. Such a framework, aptly described as a 'cookie factory' that, as Sabelis puts it, 'sells students as products and treats staff as machines' is shown to be underpinned by utilitarianisation and individualised competition (between scholars and institutions). Kamsteeg notes:

Universities have turned from homes of 'gay science' into orphanages of knowledge, transforming all their inhabitants into market competitors in a rat race for producing knowledge (citations), and pushing knowledge consumers (students) through the pipeline of the knowledge economy jungle.

Being determined by economic forces and deploying a market model of organisation is flagged by authors as being far removed from other historical traditions and intentions of the academy, in particular its role in contributing to social justice. And certainly, notions of university autonomy and academic freedom are argued to be 'dangerously approaching the point of no return when they will be on the way to becoming zombie concepts' (Donskis). Part of this corporatised and market-driven hegemony is a calcification of disciplinary divides and exacerbated privileging of those parts of the university viewed as 'useful' to market forces with a marginalising and devaluation of those not, in particular the humanities, arts, and social sciences. Abraham for example provides a detailed elaboration of European undergraduate programmes to expose the reinforcement of rigid disciplinary boundaries and resistance to interdisciplinary and transdisciplinary contexts of scholarship. The marginalising of the arts and humanities in particular is also well elaborated by Bianchini and Donskis.

The impact of this market model on academics and their scholarship is taken up in various ways in many of the chapters. The pressure on scholars to maximise efficiency and output and conform to bureaucratic surveillance in this respect is well articulated in Van Loon's autobiographical narrative: 
All of a sudden, I had to organise my life and studies to maximise efficiency rather than the pursuit of knowledge or research-related interests, face considerable future debt and worry about how to transform my university degree into an asset on the labour market.

Similarly, Sabelis, echoing a number of other authors, argues how 'the neoliberal turn was able to transform institutions of higher education into selfreferential, self-valorising quality-machines, whose "impact" was exclusively measured by its ability to meet the needs of business and government'. The drive for competitive individualised or institutionalised performance is implemented through audit and accountability cultures, 'tick boxes', layers of bureaucratisation, accountability methodologies and 'technologies of quantification. This has of course nothing to do with good research or good teaching, but with the ability to optimise quantification' (Van Loon). As Charlesworth suggests, 'the appearance of a process is materialised via administrative acts' that police scholars to conform to what is considered normative and appropriately reflective of the institution. Through such normative processes, a culture of violence is legitimised: this author shares a personal narrative of how he tends to avoid eye-contact due to personal reasons - incidentally a practice also normative in many African cultures when communicating with authority and gets punished for this in an interview by a senior authority, abusively told that 'he will not get a job if he doesn't make eye contact'. What seems an isolated and unusual incident tells a huge story of the coercive nature of higher educational institutions and constraining expectations of performance based on a particular, arguably male and Eurocentric mode of establishing academic authority. Notably, the continued hegemony of white middle-class men and whiteness, middle-classness, and masculinity in the global power structures of the academy and the stigma of working class in the university is highlighted in a number of chapters (notably, Van Loon and Charlesworth). I cannot resist recounting a personal story here in which a colleague was reviewing a new staff member who has a more gentle, responsive way of engaging, yet is extremely productive and produces excellent teaching and pedagogical work. The colleague under review was criticised for not being more assertive and dominant in her ways of teaching and academic engagement, indeed, a critique that arguably buys into a masculinist, Eurocentric mode of scholarly engagement, made all the more curious coming from a highly critical post-colonial feminist scholar. Importantly, chapters also raise the way in which current hegemonic practices in the university make unimaginable and impossible an ethics of care and appreciation of relationality and multiple forms of scholarship (for example, Sabelis). 
Some of the chapters speak powerfully to a further area of concern, that is, the side effect of current hegemonic practice in the academy, related to temporality and time. Wels talks about 'fast lane' scholarship, which results in more superficial, output-orientated scholarship. 'Fast food for the mind' and 'clock time rationality', Sabelis argues, cuts out quality, moreover 'cuts out time for the really interesting work'. And Kamsteeg elaborates on the numbing effect of the bureaucratic surveillance culture with its multiple tick boxes and forms, overwhelming academics with administration, severely undermining time and energy for intellectual pursuit. Linked to this as well as the accelerated output culture, Wels decries the lack of reading, or the ability to keep up with new literature in our areas of research:

Part of intellectual slow food is slow reading for which there is no longer sufficient time in academia.

Sabelis also highlights the lack of divide between work and the rest of a scholar's life, using rich vignettes to illustrate how the work day for an academic never ends, whether we are in the office or not.

Office times meander right through the times we spend at home, or on vacation, or wherever else in the world.

One of the most destructive effects of the multi-layered operations of contemporary orthodoxies in higher education, as elaborated by the authors, is the fragmentation, isolation, insecurity, and fear, endemic to the competitive, individualised imperatives as well as to the particular pressured temporalities outlined, which characterise contemporary scholarly life. We are made to feel alone in our time pressures and individually responsible and individually judged, often for systemic inadequacies, and as Van Loon puts it 'the institutional processes of higher education function to value and devalue, not simply by means of imposing a grading system, but also by means of personalising this (de)valuation'.

To add insult to injury in this overwhelmingly troubling picture is the repression of any resistance: the 'Stoners' will be banned (see Kamsteeg). And authors such as Van Loon and Sabelis point to the lack of organised resistance in universities, also shaped by the lack of time or space on the treadmill to organise and resist so that we are 'seduced into compliance' (Sabelis, epilogue).

Another significant negative effect offered for consideration by authors is the damage and devaluation of current teaching and learning practices, and 
the way in which the privileging of research in the neoliberal system of auditing reduces the student to 'just a number to justify the research status and existence of a professoriate' and the construction of 'teaching as a necessary burden', as Abraham puts it. Massification and loss of quality in teaching through the emphasis on the rapid and quantity-oriented production of graduates (Kamsteeg and Abraham) is arguably particularly felt by undergraduate students 'who come less and less in contact with their research-driven professors who often ignore and disdain their teaching responsibilities' (Abraham). In this kind of institutional framing, 'students in academia are treated like particles in a process of industrial rationalisation and commodification' (Wels). This produces compliant students with little curiosity, on the one hand, but also students who take on the identity of 'client' and 'calculating consumer', on the other, thus undermining the project of critical thinking and curiosity so central to scholarly practices (Kamsteeg and Wels).

The culture of insidious violence shaping academics' experiences, as argued earlier, has negative spin-offs on students too, as flagged by a number of chapters. As Charlesworth argues '(A)cademics can simultaneously materialise the appearance of their professionalism whilst acting in ways that are, fundamentally, abusive .... Authors also illuminate how the reproduction of power inequalities and the reiteration of existing social privilege through higher education has been strengthened in the current context so that those with power already - across class, citizenship, gender and other lines of privilege continue to benefit most, so that a university degree is 'merely an affirmation of their (the privileged) entitlement to superiority ... both the beneficiaries and executives of the "neoliberal turn"' (Van Loon). While for those already poor, authors like Charlesworth share narrative testimony to the inability of a university degree to make a difference, in his informants' views:

University connects to nothing. It connects us only with instability. It's just an unofficial dole office.

Authors go on to highlight one of the subtle ways in which the university continues to contribute to bolstering existing power relations, that is, through a process of erasure, the ignoring of difference of power and privilege, which, as Charlesworth argues, 'usually reduces to ignoring those who are discrepant so that good conscience can be realised via a field of co-presence that is ethnically cleansed via the anonymity arising from the way, surreptitious, interpersonal forms are used to ensure the devalued have no reason-for-being-anywhere'.

A further negative spin-off for students within the fast scholarship paradigm is how the university gears itself towards short term results, summed 
up by Sabelis as 'timescapes of employability', underpinned by 'a reductionist discourse of employability'. On the other hand, Van Loon reflects on the growing pool of unemployed doctoral students and graduates endemic to current practices in universities focused on increasing postgraduate output. Such a 'reserve army' is ultra-exploitable, and he argues the liquidation of the academy required such a standing reserve exactly because it enabled those privileged enough to work within it, to continue the institutionalised pretence of value accumulation'.

Achille Mbembe (2015b, p. 18) argues that:

Today, the decolonising project is back on the agenda worldwide. It has two sides. The first is a critique of the dominant Eurocentric academic model ... The second is an attempt at imagining what the alternative to this model could look like.

In line with Mbembe's summing up, a further contribution of this volume that I value is that it not only offers a critique but also some direction for change and the beginnings of alternative imaginaries for higher education. The chapters speak, in diverse and overlapping ways, to resistances and calls to different ways of thinking about the university and scholarship. While some may be informed by a nostalgic link to more traditional notions of the academy, others speak to specific resistances linked to the growing discomforts outlined in the critique. Authors such as Wels and Sabelis strongly call for a 'slowing down', both as practice and resistance to current orthodoxies. Implicit in many of the chapters is a call for greater attention to an ethics of care in the university, at multiple layers, including self-care. In this respect, some authors also argue for the importance of destabilising the tired binarism of body and mind and the erasure of affect and emotion in the dominant canon. Attention to pedagogical and scholarly practices and rethinking these within a framework of facilitating student agency in becoming globally conscious citizens, as Kamsteeg puts it, to 'take societal responsibility on the basis of a thorough, emotionally grounded morality that is inclusive and diverse' as well as an emphasis on generating knowledge that draws on the past to provide and think about the future within the project of facing multiple global challenges. In calling for the university to re-awaken to its political role, the authors suggest the deployment of transnational opportunities, shown to be not only a disadvantage but also a resource for social justice mobilisation (for example, Van Loon and Bianchini). Authors like Abraham and Donski also make an impassioned demand for the re-centring of liberal arts and humanities, with a particular emphasis on critical education in scholarship and politics. Importantly, we are reminded 
of the agency and indeed responsibility of scholars, especially those more secure in their position, to resist. Van Loon for example suggests 'the Robin Hood approach, in which we form our own small (Gideon's) bands of Stoners and "fight" the system wherever it manifests itself by surprise and with playful acts of defiance'. Resistance and solidarity are both implied here as well as a challenge to the alienating normative conditions of the academy. Bianchini sums up succinctly in his call on the university to 'show the courage of innovation, to break obsolescent and centralised rules, expand flexibility in the forms and quality of teaching, produce new synergies for the society, cope with the reorganisation of the human life and its relations, according to the quick changes imposed by the space-time compression'.

While I have emphasised the contributions of this book at an international level, of course the book has much to offer at a more regional level as well. Since it is predominantly European based, notwithstanding global resonances and some reference to North America and Southern Africa too, different chapters offer a rich unpacking of particularities and nuances of current and historically located European contexts. This is especially so in Donskis' chapter in terms of tracing large political and social shifts across the centuries from medieval to enlightenment to modern, and how this shapes academy. Furthermore, the chapters authored by Abraham and Bianchini present a comprehensive picture of current policies within the European Union (EU) in relation to higher education, a keen historical overview of the academy in Europe aimed at understanding the 'dismal stage of the undergraduate studies in Europe today' (Bianchini), as well as a rich historical overview of European liberal arts and its transnational roots and shifts and changes over the centuries. Bianchini for example flags the post-Cold War as a period of reimagining the university and unpacks policies of internationalisation and transnationalism resulting in student and faculty mobility, and how these impact on the globalising effect of particular traditions of scholarship, serving to disrupt rigid nation-state insularity. In this respect, the book insists on the specificities of our contexts and their histories, and illustrates how contextual archival and current work provides valuable insight for understanding the current context, particularly helpful for scholars wishing to understood higher education and areas of contestation in contemporary European contexts. We also get a good sense of current nuances and differences in the way in which neoliberal practices are infiltrating and shaping universities in different national contexts across North America and Europe through the biographical account of Van Loon and his own experiences in different universities across these contexts.

On the other hand, as my subjective responses to this work attests, the book is not simply of value in European contexts. On the contrary, since we live in a 
globalised world and an increasingly globalised academy, which remains dominated in many parts by the north and west (indeed the very European context so well unpacked here), this book of course has large resonance and value for global southern critiques and transnational thinking around the future of the university, particularly in terms of critical, social justice and decolonial projects, or whatever term is drawn on at a particular moment.

As one emerges from reading these essays - their different tones and emphases notwithstanding - what stands out is a bold and dedicated passion for social justice, for imagining a different academy that can make a difference. Also evident in all the authorial voices, even though they are diversely located in terms of careers, disciplines, geopolitical contexts and individual lives, is their long embeddedness in the matters they address, and a courage to share personal experiences and challenges as well as an honesty in recognising their own complicity. In many ways I find that these chapters model an alternative scholarly practice that speaks to the critiques they make, even while following what appears to be a normative scholarly product such as an edited volume. The valuing of affect and subjective experience models resistance to the binarisms of body/mind, emotion/rationality, femininity/masculinity that underpins the historical traditions of colonialist, empiricist scholarship that have been instrumental, or at best complicit, in the practices of racist genocide, class exploitation, and environmental destruction that are implicated in our current global and planetary challenges. In this respect, I especially admire how the authors resisted the normative tradition of 'writing themselves out' of the academic story they told; rather, most chapters are threaded through with a subjective voice, sharing at times uncomfortable personal stories. Such personalised narratives, as a strong thread through many of the chapters, counteract traditions of objectivity and 'othering' of the subject of study. They not only provide anecdotal evidence and richness to the text but also model a project of destabilising dominant academic discourse and institutional practice in which embodiment, emotions, and experience are erased. Also, very special about this collection of essays is how the authors dialogue with each other - every author has read and enthusiastically engaged in everyone else's piece and the conversations and resonances are a golden thread through the text. Again, this serves as a positive intervention in our individualised and competitive hegemonies where scholars tend to cite others in a kneejerk attempt to prove our own authority rather than to engage meaningfully with their arguments, or when we read only to undermine and devastate others in our self-aggrandisement project, as prescribed by current orthodoxies. Here something else is happening: authors are reading each other constructively, to dialogue with each other's arguments, to add emphasis to what is being said by 
others, and/or to complement their own understandings for a strengthened analysis.

To sum up, this rich volume of essays reminds us, as Alexis Shotwell (2015, p. 7) puts it, that: 'We're complicit, implicated, tied in to things we abjure'. But the incisive analyses in this book also fine-tune our critique and reflexivity with respect to our positionality in our complicity and implicated-ness. This book inspires the reader with a critical hope to open up spaces for resistance and change, even if only in small pockets and through slow movements, and to allow a different 'imaginary' of what the university can be and do.

\section{References}

Bauman, Z. (2000). Liquid Modernity. Cambridge, Polity Press.

Bauman, Z., \& Donskis, L. (2013). Moral Blindness: The Loss of Sensitivity in Liquid Modernity. Cambridge, Polity Press. (especially Chapter 4).

Bauman, Z., \& Donskis, L. (2016). Liquid Evil:Living with TINA. Cambridge, Polity Press.

Mbembe, A. (2015a). The politics of o\%. City Press, 1 November 2015. Retrieved from https://citypress.news24.com/Voices/The-politics-behind-the-0-20151030.

Mbembe, A. (2015b). Decolonising knowledge and the question of the archive in public lectures at Wits Institute for Social and Economic Research (WISER), 30 Apr 2015. Johannesburg, South Africa. Retrieved from http://www.staugustine.ac.za/sites/ default/files/ctools/13.\%20Mbembe\%20-\%2oDecolonizing\%20Knowledge...\%20 $\% 282015 \% 29$.pdf.

Shotwell, A. (2015). Against Purity: Living Ethically in Compromised Times. Princeton, NY, Princeton University Press. 